Guillaume-Thomas Raynal, Histoire philosophique et politique des établissements et du commerce des Européens dans les deux Indes. Edition critique. Comité éditorial composé d'Anthony Strugnell (dir.), Andrew Brown, Cecil Patrick Courtney, Georges Dulac,Gianluigi Goggi et Hans-Jürgen Lüsebrink. Tome I. Ferney-Voltaire, Centre international d'études du XVIIIe siècle, 2010.

Marie Leca-Tsiomis

\title{
OpenEdition
}

Édition électronique

URL : https://journals.openedition.org/rde/4763

DOI : $10.4000 /$ rde. 4763

ISSN : 1955-2416

Éditeur

Société Diderot

Édition imprimée

Date de publication : 15 décembre 2010

Pagination : $175-177$

ISBN : 978-2-9520898-3-8

ISSN : 0769-0886

Référence électronique

Marie Leca-Tsiomis, « Guillaume-Thomas Raynal, Histoire philosophique et politique des établissements et du commerce des Européens dans les deux Indes. Edition critique. Comité éditorial composé d'Anthony Strugnell (dir.), Andrew Brown, Cecil Patrick Courtney, Georges Dulac,Gianluigi Goggi et Hans-Jürgen Lüsebrink. Tome I. Ferney-Voltaire, Centre international d'études du XVIIIle siècle, 2010. », Recherches sur Diderot et sur l'Encyclopédie [En ligne], 45 | 2010, mis en ligne le 15 janvier 2011, consulté le 30 juillet 2021. URL : http://journals.openedition.org/rde/4763 ; DOI : https://doi.org/ 10.4000/rde.4763

Ce document a été généré automatiquement le 30 juillet 2021.

Propriété intellectuelle 
Guillaume-Thomas Raynal, Histoire philosophique et politique des établissements et du commerce des Européens dans les deux Indes. Edition critique. Comité éditorial composé d'Anthony Strugnell (dir.), Andrew Brown, Cecil Patrick Courtney, Georges Dulac,Gianluigi Goggi et Hans-Jürgen Lüsebrink. Tome I. Ferney-Voltaire, Centre international d'études du XVIIIe siècle, 2010.

Marie Leca-Tsiomis

\section{NOTE DE L'AUTEUR}

Contient : Livre I. Découvertes, guerres \& conquêtes des Portugais dans les Indes Orientales, éd. Peter Jimack; II. Etablissemens, guerres, politique\&commerce des Hollandais dans les Indes Orientales, éd.Guido Abbattista; III. Etablissemens, commerce \& conquêtes des Anglois dans les Indes Orientales, éd. Anthony Strugnell ; IV. Voyages, établissemens, guerres \& commerce des 
François dans les Indes Orientales, éd. Florence De Souza ; V. Commerce du Danemarck, d'Ostende, de la Suède, de la Prusse, de l'Espagne, de la Russie, aux Indes Orientales, éd. Muriel Brot ; index de Raynal ; variantes ; les contributions de Diderot aux livres I-V par Gianluigi Goggi. xxxi 770 pages.

Raynal et Bonne, Tableaux, atlas et cartes de l'Histoire philosophique et politique des établissements et du commerce des Européens dans les deux Indes. Reproduction en fac-similé des éditions de 1774 et 1780 . Présentation et notes par Andrew Brown. Ferney-Voltaire, Centre international d'études du XVIIIe siècle, 2010.

1 Le premier volume de la nouvelle édition, si souhaitée et attendue, de l'Histoire des deux Indes est paru et on doit s'en féliciter. Première édition critique et aussi première édition complète moderne, la précédente remontant à 1820 , cette très grande entreprise internationale à laquelle collaborent une trentaine de chercheurs comptera quatre volumes renfermant les dix-neuf livres du texte de Raynal et deux volumes complémentaires dont l'un, celui de l'Atlas, vient également de paraître.

2 Le texte choisi pour cette édition de l'Histoire des deux Indes est celui de la dernière édition révisée par Raynal, en 1780 . Mais les éditions précédentes $(1770,1774)$ sont présentes grâce aux variantes, de même que sont signalées dans le texte, par des appels de notes, les contributions de Diderot.

3 Ce premier volume contient les cinq premiers livres, consacrés aux établissements européens aux Indes orientales, respectivement à ceux des Portugais, puis des Hollandais, des Anglais, des Français, le dernier traitant du Danemark, d'Ostende, de la Suède, de la Prusse, de l'Espagne et de la Russie. Confié aux meilleurs spécialistes, ce volume dense mais aux pages aérées, est un modèle tant pour ce qui concerne les introductions particulières à chaque livre que pour les annotations précises, judicieuses, émanant d'une érudition exacte et jamais pesante. La lecture désormais aisée de cette vaste histoire du commerce international au XVIIIe siècle est passionnante, et, après un si long temps de relégation, l'intérêt qu'elle suscite et dont témoignent les travaux de recherche déjà en plein essor ne pourra que se développer.

Osera-t-on, concernant une si remarquable édition, émettre une suggestion : celle d'une introduction historique qui permette de situer dans son contexte l'Histoire des deux Indes elle-même. Mais sans doute faudra-t-il attendre un volume suivant, c'est-à-dire l'avancement de l'édition en cours.

5 Quant à ce qui concerne plus particulièrement notre revue, à savoir la collaboration de Diderot, les apports de cette édition me paraissent tout à fait essentiels, notamment grâce à G. Goggi à qui l'on doit la liste détaillée des contributions du philosophe à ces quatre premiers livres. Mis à part les interventions authentifiées en quelque sorte par les manuscrits du fonds Vandeul, on sait que de nombreuses autres interventions eurent lieu, notamment dans l'édition de 1780 d'HDI.Celles qui peuvent " avec vraisemblance être attribuées à Diderot ", formule qui évoque celle de John Lough et Jacques Proust dans le cas,homologue,des articles non signés de Diderot dans la seconde partie de l'Encyclopédie (DPV,V) sont signalées ici, avec les références qui justifient ces choix convaincants.

6 On a, durant de longues années, considéré que la contribution de Diderot était uniquement faite d'ajouts philosophico-politiques, nés de la lecture du texte de Raynal, et constituant une écriture en marge ou "fragmentaire". Mais les travaux de G. Goggi ont, depuis, montré que Diderot avait été bien plus amplement impliqué dans l'ouvrage, 
notamment parce qu'il avait aussi collaboré à la préparation du texte, à la recherche des sources, et ce dès la première édition de l'HDI. Et, comme Goggi le souligne à nouveau dans son introduction, l'intervention du philosophe, dans "l'exercice de l'éloquence qui marque l'introduction d'un point de vue politique», subvertit le sens général de l'Histoire des deux Indes « jusqu'à transformer le texte de l'abbé Raynal en véritable "machine de guerre"» (Goggi, xxxiii). Le système des annotations qui fournit aussi souvent que possible les sources donne mainte occasion de le vérifier : voir par exemple la véhémente exhortation diderotienne comparée à sa source chez Bolts, à la fin du livre III.

7 Quel intérêt considérable enfin pour nous de pouvoir lire désormais ces interventions diderotiennes au sein même de l'ouvrage auxquelles elles appartiennent et non plus par bribes ou comme des pensées détachées! Tout change de notre regard et de notre lecture grâce à cette re-contextualisation.

8 En même temps que ce premier volume, est publié le superbe facsimilé des cartes et des tables publiées dans l'Atlas paru en 1780 sous la signature de Raynal et Bonne. Andrew Brown accompagne des notes nécessaires cette reproduction d'un format exceptionnel $(27 \times 37)$, quasiment celui du petit in-folio. 